\title{
A Festschrift to Dr. Albert "Mickey" Stunkard: Celebrating a Lifetime of Obesity and Eating Disorders Research (Born February 7, 1922, New York City; Died July 12, 2014, Bryn Mawr, PA)
}

\author{
Marion M. Hetherington ${ }^{1}$
}

Published online: 19 February 2016

(C) Springer Science+Business Media New York 2016

This special section has been written in recognition of the outstanding contribution made by Dr Albert J. "Mickey" Stunkard to the field of obesity research, a colleague, mentor and friend whose loss is still keenly felt. It is fitting that a journal named Current Obesity Reports dedicated to advance knowledge in the field of scientific discovery of obesity mechanisms and clinical care of patients with obesity should honour Dr. Stunkard in this way. We have gathered together a range of scientists to commemorate the exceptional impact that Mickey has had as a pioneer in this field. Mickey made his mark in 1955 publishing the first paper on the night-eating syndrome in the American Journal of Medicine, he then proceeded to publish more than 500 papers during his long and fruitful career. His paper describing the development of the three-factor eating questionnaire has been cited more than 2000 times and is used widely across the world to assess cognitive restraint, disinhibition and perceived hunger. Mickey's publications reveal a diversity of interests within the fields of eating disorders and obesity, from the genetics of obesity explored through twin studies to the stigma applied to individuals who are obese and from the socioeconomic gradient evidenced in the prevalence of overweight and obesity to specific eating problems experienced by some individuals such as binge eating and the nighteating syndrome. This wide range of topics explored by Mickey Stunkard is all the more remarkable when one considers that his scientific career began long before the internet era and the advance of the personal computer. It is testimony to his determination and enthusiasm that he was able to combine his successful research endeavours with clinical practice. He treated people with obesity and enhanced therapeutic approaches using behaviour modification techniques. He supported the use of bariatric surgery since he had found that patients reported improvements in appetite control and healthy eating alongside significant weight loss. Therefore, his reach and influence went well beyond his scientific peers, touching the lives of many patients and their families. It is apparent from the papers for this section that he was held in great regard and with much affection by his colleagues. Dr Stunkard was a highly respected, much admired, and influential scientist who combined outstanding research with clinical care and mentorship of many scientists and clinicians throughout his long and distinguished career. His enthusiasm, intelligence and personal commitment to obesity research have been inspirational to us all, and he is much missed.

Marion M. Hetherington

m.hetherington@leeds.ac.uk

1 School of Psychology, University of Leeds, Leeds, UK 